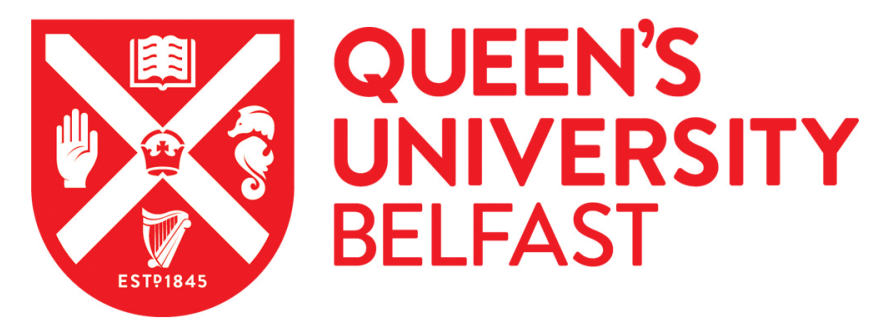

\title{
Illness perceptions and coping in physical health conditions: A meta- analysis
}

Dempster, M., Howell, D., \& McCorry, N. K. (2015). Illness perceptions and coping in physical health conditions: A meta-analysis. Journal of Psychosomatic Research, 79(6), 506-513.

https://doi.org/10.1016/j.jpsychores.2015.10.006

Published in:

Journal of Psychosomatic Research

Document Version:

Peer reviewed version

Queen's University Belfast - Research Portal:

Link to publication record in Queen's University Belfast Research Portal

Publisher rights

(c) Elsevier Ltd. This manuscript version is made available under the CC-BY-NC-ND 4.0 license http://creativecommons.org/licenses/by-nc$\mathrm{nd} / 4.0 /$ which permits distribution and reproduction for non-commercial purposes, provided the author and source are cited.

\section{General rights}

Copyright for the publications made accessible via the Queen's University Belfast Research Portal is retained by the author(s) and / or other copyright owners and it is a condition of accessing these publications that users recognise and abide by the legal requirements associated with these rights.

Take down policy

The Research Portal is Queen's institutional repository that provides access to Queen's research output. Every effort has been made to ensure that content in the Research Portal does not infringe any person's rights, or applicable UK laws. If you discover content in the Research Portal that you believe breaches copyright or violates any law, please contact openaccess@qub.ac.uk. 
Illness Perceptions and Coping in Physical Health Conditions: A Meta-Analysis

${ }^{1}$ Martin Dempster PhD, ${ }^{2}$ Doris Howell PhD and ${ }^{3}$ Noleen K. McCorry PhD

\author{
${ }^{1}$ School of Psychology, Queen’s University Belfast, Northern Ireland \\ ${ }^{2}$ Lawrence Bloomberg Faculty of Nursing, University of Toronto, Toronto, ON. \\ 3Marie Curie Cancer Care, Marie Curie Hospice Belfast, Northern Ireland
}

Corresponding author:

Martin Dempster

School of Psychology, Queen’s University Belfast, University Road, Belfast, Northern Ireland, BT7 1NN

Tel: +442890975547

Email: m.dempster@qub.ac.uk 


\begin{abstract}
Objective: There is a considerable body of research linking elements of Leventhal's Common Sense Model (CSM) to emotional well-being/distress outcomes among people with physical illness. The present study aims to consolidate this literature and examine the evidence for the role of coping strategies within this literature.

Methods: A systematic review was conducted where the outcomes of interest were: depression, anxiety and quality of life. A total of 1050 articles were identified and 31 articles were considered eligible to be included in the review.

Results: Across a range of illnesses, perceptions of consequences of the illness and emotional representations were consistently the illness perceptions with the strongest relationship with the outcomes. Coping variables tend to be stronger predictors of outcomes than the illness perception variables. The evidence for the mediating effect of coping was inconsistent. Conclusions: Illness perceptions and coping have an important role to play in the explanation of distress outcomes across a range of physical health conditions. However, some clarity about the theoretical position of coping in relation to illness perceptions, and further longitudinal work is needed if we are to apply this information to the design of interventions for the improvement of psychological health among people with physical health conditions.
\end{abstract}

Keywords:

Illness Perceptions; coping; psychological distress; meta-analysis 


\section{Introduction}

The Common Sense Model (CSM)[1] posits that when an individual is confronted with an illness or health condition, they will attempt to assign meaning to this illness by accessing their cognitive and emotional representations of illness (illness perceptions). The CSM proposes that individuals will develop coping procedures (based on their illness perceptions), which will then be evaluated in terms of their success. The result of this evaluation may be a change in coping strategy and/or a change in perceptions about the illness. The CSM, therefore, illustrates the relationship between cognitive and emotional representations of an illness and coping strategies.

Originally, the CSM viewed coping strategies as behavioural outcomes and research based on the model has examined whether illness perceptions are important predictors of coping procedures in terms of behavioural outcomes such as medication adherence [2-4], attendance at cardiac rehabilitation [5] and self-care in diabetes [6]. Subsequently, the CSM has been used as a model to explain physical or psychological outcomes (eg. glycaemic control [7]; quality of life [8]). This research has usually considered coping as a concept broader than behavioural outcomes and has also included cognitive and emotional strategies that a person might use to manage a potentially negative situation. For example, in this context, coping is taken to mean avoidant coping strategies, such as behavioural disengagement (giving up attempts to manage the situation); approach coping strategies, such as acceptance (learning to live with the situation); emotion-focused coping strategies, such as venting (expressing negative feelings); and problem-focused coping strategies, such as active coping (doing something to make the situation better). These categories are not mutually exclusive.

There is a considerable body of research linking elements of the CSM to psychological outcomes among people with physical illness. However, using the CSM to 
explain psychological outcomes is an extrapolation of the original model and this extrapolation has clearly left researchers unsure about the role of coping (now conceptualised in its broader sense). Although the CSM includes emotional representations of the illness and emotional coping strategies as considerations, the CSM does not explicitly address psychological outcomes. Not surprisingly, therefore, the application of the CSM to explain psychological outcomes has been open to individual researchers' interpretations, which has resulted in inconsistencies around which elements of the CSM are considered to be important in explaining psychological outcomes (i.e the relevance of emotional representations) and confusion about how the elements of the CSM are considered to relate to each other (i.e. whether or not coping procedures are hypothesised to mediate the relationship between illness perceptions and outcomes).

For example, Price et al. [9] and Dempster et al. [10] both hypothesised that illness perceptions and coping variables are important when explaining variation in distress outcomes among people with cancer. Yet, Dempster et al. tested a model that assumed the relationship between illness perceptions and distress would be mediated by coping, whereas Price et al. did not make any assumptions about mediation. Furthermore, Benyamini et al. [11] do not include a measure of coping in their examination of the relationship between illness perceptions and quality of life among people with dermatitis, even though the CSM is presented as the theoretical model justifying their research. Indeed, Wenninger et al. [12] merge the concepts of illness perceptions and coping. They assessed illness perceptions among adults who have survived childhood cancer, and referred to the illness perception measures as coping strategies. Consequently there is a need to bring some clarity to this area.

The questionnaires most commonly used in the literature to assess illness perceptions are the Illness Perception Questionnaire-Revised (IPQ-R) [13] and the Illness Perception Questionnaire (IPQ) [14]. The IPQ assesses 5 illness perceptions: identity (perceptions of 
symptoms associated with the illness), controllability/curability of the illness, timeline for the illness, consequences of the illness and cause of the illness. The IPQ-R added items designed to assess illness coherence (the person's perceptions of the extent to which they understand the illness) and emotional representations (the extent to which the person's illness makes them experience symptoms of anxiety or depression). The authors of the IPQ-R also divided the timeline dimension into 2 factors (timeline cyclical and timeline acute/chronic) and divided the cure/control dimension into 2 factors (personal control and treatment control). Timeline cyclical refers to the perception of the cyclical nature of the illness across time; timeline acute/chronic is the person's perception about the illness passing quickly or not. Personal control refers to perceptions of the person's ability to control the illness, whereas treatment control refers to perceptions about the effectiveness of any treatment or the effectiveness of medical personnel to control the illness.

The Brief IPQ [15] has been developed more recently. It uses a single item each to measure the illness perceptions of consequences, timeline, personal control, treatment control, identity, concern, understanding and emotional response. However, using a single item to address each construct makes the Brief IPQ more prone to random measurement error than the multi-item scales of the IPQ and IPQ-R.

Given the lack of consistency in the application of the CSM when focusing on psychological outcomes among people with physical illness, a review of the empirical evidence about the relationships between illness perceptions, coping and psychological health outcomes will be useful in contributing to deliberations that will provide theoretical clarity. A previous review of the CSM exists [16] but most of the research in this area has been published since this review was conducted.

The aim of the present review, therefore, is to determine the following: 
1. The extent to which illness perceptions (as assessed by the IPQ-R or IPQ) and coping strategies explain emotional outcomes (depression, anxiety, or quality of life) among people with physical illness.

2. The evidence for the mediating role of coping strategies in this relationship.

\section{Method}

In comparison to the IPQ and IPQ-R, the use of any other measure to assess illness perceptions is relatively rare. The exception to this is the Brief IPQ, but it is not comparable to the IPQ or IPQ-R given the measurement problems outlined in the introduction section of this paper. On the other hand, there is less consensus in the literature regarding which coping measures are appropriate within this body of research. Therefore, this review focused on studies that employed the IPQ or IPQ-R, but did not place any restrictions on the choice of coping measure.

The Web of Science, Psycinfo and Medline databases were searched for relevant articles on $13^{\text {th }}$ August 2013. In the Web of Science a cited author search was performed to identify any articles that have cited the original IPQ [14] or the original IPQ-R paper [13]. This resulted in 991 records. Grey literature was not examined as research found in the grey literature is often of lower quality and unlikely to affect the conclusions of a review [17].

In Psycinfo the thesaurus term 'emotional states’ was combined (using the AND operator) with the following search term: (illness perception* OR illness cognition* OR illness representation*). This resulted in a total of 134 records. The thesaurus term 'emotional states' is a very broad search term that includes over 44 different emotional states.

In Medline the thesaurus terms 'adjustment disorders', 'anxiety disorders', and 'mood disorders' were combined (using AND) with the following search term: (illness perception* OR illness cognition* OR illness representation*). This resulted in a total of 41 records. The 
Medline thesaurus terms were chosen as the most closely resemble the Psycinfo term ‘emotional states’.

These search strategies were designed to increase the likelihood that relevant articles were not missed, while sacrificing precision. Hence, it is likely that relevant articles would be found, but many irrelevant articles would also be identified.

After removing duplicates, the title and abstract of all records were assessed against the eligibility criteria. Where articles clearly did not meet the eligibility criteria, they were excluded at this stage. The full text publication of all other articles was then retrieved and the eligibility criteria were re-applied to these articles. The outcome of this process is that 37 articles were considered eligible to be included in the review (see Figure 1). The reference lists of these articles were also searched for any additional relevant articles, but none were found. Assessment for eligibility was conducted independently by a second rater, with any disagreements being resolved by consensus.

- Figure 1 here -

The eligibility criteria applied at each stage were that the article should: include a quantitative assessment of coping; include either the IPQ or IPQ-R; include a measure of anxiety, depression or quality of life; include information about the relationships between illness perceptions and coping and psychological distress or quality of life; include a sample of people with a physical illness.

Of the full-text articles excluded on the basis of the eligibility criteria, 21 were excluded because they did not include a coping measure.

Given that this review is concerned with the observed relationships between variables, a focus on the external validity (more than internal validity) of studies was considered to be appropriate. An indication of external validity of each study was determined by examining the potential selection bias, the data collection methods, withdrawals and drop-outs and the 
sample size. The elements relevant to external validity in the Effective Public Health Practice Project quality assessment tool (http://www.ephpp.ca/tools.html) were used to guide this quality assessment.

When the data collection tools were examined at this assessment, a further 6 articles were excluded because they had not used the IPQ/IPQ-R subscale scores in their analyses. All other articles were retained for review.

Correlation coefficients representing the relationship between illness perceptions and outcomes and between coping strategies and outcomes were extracted for meta-analysis. Where data was not available in the published paper, authors were contacted to obtain the relevant correlations. Information about regression analyses, including any investigations of mediation were extracted for narrative synthesis.

Where possible, weighted average correlation coefficients were calculated using the Hunter \& Schmidt random-effects model [18].

\section{Results}

Of the remaining 31 articles reviewed, it was apparent that there was some overlap in the data presented in different articles. In some cases, baseline data from a longitudinal study were presented and then the longitudinal analysis was presented in a separate article. In other cases, a subset of participants or scores were re-analysed in a separate article. These articles were grouped and counted as a single record. Therefore, the Oesophageal Cancer Study refers to the 3 articles by Dempster et al. $[10,19,20]$; the Huntington's Disease Study refers to the articles by Helder et al. [21] and Kaptein et al. [22]; and the Head/Neck Cancer Study refers to the articles by Llewellyn, McGurk and Weinman [23-25]. Consequently, a total of 26 distinct studies were reviewed.

See Table 1 for a description of the studies reviewed.

- Table 1 here - 
The validity assessment indicated little variation across studies. Most of the studies were conducted using a convenience sample obtained by sending a questionnaire survey in the post to people on a database (eg. a patient support group database), or by recruiting from attenders at an outpatients clinic. All of the studies used measures with good evidence for reliability and validity. Therefore, the only difference considered to be important in terms of the external validity of the research is encapsulated in the sample size, which is reported in Table 1.

The majority of the studies reviewed examined relationships between illness perceptions, coping and outcomes using a cross-sectional design. Although the strength of conclusions that we can draw from cross-sectional studies is limited, the majority of studies reviewed used this type of design. Therefore, their results are included here, in order to present a comprehensive picture of the current state of the research. These cross-sectional studies will be synthesised first, categorised by the outcome, followed by a synthesis of the studies using a longitudinal design. Outcomes are classified into depression, anxiety and quality of life. These outcomes were not specified a priori, but were the outcomes identified in the retrieved literature. For each outcome, the correlations will be examined first, followed by a synthesis of the regression analyses.

\section{Cross-sectional Studies}

Depression. Twelve studies provided information on the cross-sectional relationship between illness perceptions, coping and symptoms of depression. Six of these studies used the IPQ to assess illness perceptions and 6 studies used the IPQ-R. Most of these studies used the Hospital Anxiety and Depression Scale (HADS) to measure the outcome (see Table 1).

The weighted effect size for the correlations between illness perception and coping variables and depression are provided in Table 2.

- Table 2 here - 
One study [26] used analysis of variance to compare groups of people with different levels of depression on the IPQ variables. Commensurate with the findings in Table 2, this study also found that consequences and control/cure were the strongest discriminators of depression.

The coping variables are measured using several different instruments, which assess different coping strategies, making a synthesis of findings difficult. Indeed, even where there was sufficient similarity in the definition of coping strategies to allow a calculation of a metacorrelation (positive focus, venting, acceptance, behavioural disengagement), most of these showed a significant degree of heterogeneity (see Table 2).

Eleven studies examined the relative contribution of illness perceptions and coping to the explanation of the variance in depression via hierarchical regression. When illness perceptions were entered first [10,19,20,29-34], the weighted average contribution to the variance in depression was $27.5 \%$ and for coping it was $7.2 \%$. When coping was entered first, the additional contribution to the explanation of variance in depression for illness perceptions was small in 2 studies (up to 9.2\%) [28,36] and large in another (33\%) [35] and for coping it was $10 \%$ in two studies [35,36] and 25\% in another [28]. In 7 of the 11 studies the coping variables were the strongest predictors in the final regression model.

Anxiety. Nine studies provided information on the cross-sectional relationship between illness perceptions, coping and symptoms of anxiety. Three of these studies used the IPQ to assess illness perceptions and 6 studies used the IPQ-R. Most of these studies used the HADS to measure the outcome (see Table 1).

The weighted effect size for the correlations between illness perception and coping variables and anxiety are provided in Table 3, which shows that the emotional representations variable has a strong, positive association with anxiety and anxiety is moderately associated with the illness cognitions of consequences and identity and the coping variable venting. 
Consequences and identity were also found to be the strongest discriminators of anxiety in a study not included in the meta-analysis because of the lack of comparable statistics [26].

- Table 3 here -

Ten studies examined the relative contribution of illness perceptions and coping to the explanation of the variance in anxiety via hierarchical regression. When illness perceptions were entered first $[10,19,20,29,31-34,37]$, the weighted average contribution to the variance in anxiety was $26.8 \%$ and for coping it was $7.4 \%$. When coping was entered first $[28,35,36]$, the weighted average contribution to the explanation of anxiety was $12.2 \%$ for illness perceptions and $27.4 \%$ for coping variables. In 7 of the 10 studies the coping variables were the strongest predictors in the final model.

Quality of life. Eight studies claimed to assess quality of life as an outcome measure and they all used different questionnaires, most of which were disease-specific (Dermatology Quality of Life Index, Inflammatory Bowel Disease Questionnaire, Minnesota Living with Heart Failure Questionnaire and the EORTC Quality of Life C30 questionnaire), but some were generic (Quality of Life Scale, Short Form 36, Short Form 12) and 1 study used an individualised measure (Patient Generated Index). Therefore, although all the disease-specific and generic measures overlapped in their conceptualisation of quality of life (which included physical, social and emotional functioning), the findings are not considered sufficiently homogenous for statistical meta-analysis.

The reported correlation coefficients between the illness perceptions and outcome variables suggest that quality of life has a weak relationship with personal control $(r=-0.25$ to 0.08 ), treatment control ( $r=-0.28$ to 0.09 ) and illness coherence ( $r=-0.25$ to 0.17$)$; a moderate to strong relationship with identity $(r=0.27$ to 0.60$)$ and emotional representations $(r=0.34$ to 0.58$)$; and a strong relationship with consequences $(r=0.40$ to 0.59$)$. 
When the illness perception variables are entered into a regression model prior to coping strategies, they explain $21 \%$ to $35 \%$ in quality of life, with the coping variables adding an additional $2 \%$ to $7 \%$. However, in one study [21], illness perception variables and coping variables were included separately as covariates in separate regression models. In this case, the illness perception variables explained $25 \%$ of the variance in quality of life, and the coping variables explained 52\%.

\section{Longitudinal Studies}

Nine studies examined the relationship between illness perceptions, coping and outcomes using a longitudinal design. The outcomes in most studies were either anxiety or depression and the time lag ranged from 6 months to 12 months (see Table 1). Eight of these studies explored whether baseline illness perceptions and coping variables predicted outcomes at a later point in time. The other study (Oesophageal Cancer study) examined the relationship between changes in illness perceptions, coping and outcomes over time.

This latter study created clusters of participants based on the changes in their IPQ-R scores and found that this explained 3\% of the variance of change in anxiety scores and $4 \%$ of the variance in change in depression scores over a 12 month period. The change in coping scores added an extra $4 \%$ and $6 \%$ to the regression models respectively.

Six of the remaining 8 studies [25,29,39-41] included a baseline measure of the outcome as a predictor variable in the regression model and in all these cases this variable accounted for a substantial proportion of the variance in the outcome variable. The illness perception variables contributed an additional $6 \%$ to $15 \%$ to the explanation of variance in the outcome variables and the coping variables contributed an additional $1 \%$ to $9 \%$ to the explanation of the outcome variance. When the baseline outcome variables were not used as predictors [33,39], the percentage of variance contributed by illness perceptions rose to as much as $29 \%$, and the percentage of variance contributed by coping variables rose to as much 
as $13 \%$. Consequences, identity and timeline were found to be significant illness perceptions and avoidance/ passive type coping strategies were the strongest coping predictors across these longitudinal studies.

All but 2 of the 9 longitudinal studies included participants who had been diagnosed with their condition for a considerable period. Average duration of diagnosis for participants ranged from 4 to 26.6 years. Two studies [25,33] obtained baseline measures at diagnosis and prior to the commencement of treatment. However, given the differences in the type of analysis used in the longitudinal studies, it is not possible to discern whether the timing of assessment of illness perceptions (in relation to diagnosis) influenced the findings.

Five of the 9 studies examined the mediating role of coping in this longitudinal design and none found any evidence of this.

In all of the longitudinal studies, little evidence was found of changes over time in illness perceptions or coping strategies.

\section{Discussion}

The review found that, across a range of illnesses, illness perceptions explained between $25 \%$ and $30 \%$ of the variance in the emotional health outcomes in cross-sectional studies, before any coping variables were considered. This is a notably homogenous finding given the range of illnesses covered in the research. In addition, perceptions of consequences of the illness and emotional representations were consistently the illness perceptions with the strongest relationship with these outcomes. Perceptions about the chronicity of the illness timeline tend to show a weak relationship with psychological distress outcomes. Previous research [43-45] has questioned the construct validity of the acute/chronic timeline scale on the IPQ-R, and this validity issue might explain the weak relationship between this subscale and psychological health outcomes. It could also be the case that the concepts of acute and chronic timeline are not opposites among people with long term conditions, especially 
conditions with a poor prognosis. For example, people might report that their condition will be permanent (indicating perceptions of a chronic timeline), but that it will also last a short time (indicating perceptions of an acute timeline), because they believe they do not have a long time to live.

The strong relationship between emotional representations and psychological outcomes in the studies reviewed raises the question of tautology. When research focuses on psychological distress and related variables as outcome variables, then there is a need to be more critical about the inclusion of emotional representations as a predictor. Of course, there are usually differences in these variables, at least theoretically, in that emotional representations are specific to the illness under investigation and the outcome variables are usually more generic. Nevertheless, a person's general level of distress is highly likely to be influenced considerably by the distress they experience as a result of their long term condition and this revelation in a research study will come as no surprise to anyone, and do little to forward our understanding of the person's situation.

There was significant heterogeneity across studies in the relationship between identity and anxiety or depression. This is not surprising given that the identity scale is often amended to make it more specific to the condition under investigation and, therefore, there is likely to be heterogeneity across studies in terms of the content of the identity scale.

An aim of this review was to examine the role of coping in the relationship between illness perceptions and psychological health outcomes. The review found that when coping and illness perceptions were considered together in a regression model, the coping variables tend to be stronger predictors of outcomes than the illness perception variables. Coping was assessed in different ways across the studies but, of the coping variables assessed, behavioural disengagement, venting emotions and denial appear to show the strongest relationship with psychological distress. Indeed, in cases where coping was found to mediate 
the relationship between illness perceptions and outcomes, it was at least one of these three variables that were identified as a mediator, and where no evidence of mediation was found, the coping instrument used did not assess any of these three coping strategies specifically.

So, variables generally considered to represent avoidant coping appear to be the strongest predictors of psychological distress. Consequently, there is little evidence from this body of literature to support the promotion of positive coping among people with long term conditions. But, encouraging an avoidance of avoidant coping strategies might be more successful $[46,47]$. Perhaps this speaks to the lack of precision in the definition of positive coping. However, it must be noted that, given the range of illnesses covered in the review, it might be the case that different coping strategies are best for different conditions. For example, avoidant coping might be more appropriate for short-term or less severe conditions. Importantly, this review did not aim to determine the most effective coping strategies for a range of physical illnesses and therefore conclusions about the relationship between coping and distress are, at best, tentative. Rather, the focus of this review was on how coping is operationalized in relation to illness perceptions.

It is clear in this review that the role of coping is not operationalized consistently across studies in this area, even though the same theoretical model (Leventhal's Common Sense Model) is usually cited as the model that underpins the research design. In some cases, coping is not measured at all and these studies were excluded from the review; in some cases coping is treated as a covariate and in some cases it is treated as a mediator. Indeed, this confusion in the operationalization of the model results in potentially misleading research findings. Most of the research conducted in the area tends to use regression analyses where illness perceptions are entered into the model before coping strategies. As a consequence, coping is reported as adding little explanation to the outcome variables beyond that explained by illness perceptions and the implication is that coping variables are less important than 
illness perceptions. However, in the few cases where coping variables are added to the regression model first, they are seen to explain a considerable proportion of the variance in the outcomes, which could change our interpretation of the role of coping in the model. Furthermore, when illness perceptions and coping variables are included in the regression model, coping is often the strongest predictor.

It is likely that this confusion in the role of coping results from an extrapolation of the CSM to the explanation of distress outcomes - an outcome that is not explicitly addressed in the CSM. Although the extension of the CSM to distress outcomes is logical, the nature of the relationship between the components of the CSM and distress outcomes needs further exploration to establish a model that is focused on explaining distress outcomes.

In considering the role of illness perceptions and coping in the explanation of distress outcomes, it is worth considering the extent to which illness perceptions are capturing an element of coping. Recently some questions have been asked about the content validity of the IPQ-R, and the extent to which the measurement of illness perceptions using this instrument is confounded with coping appraisals. For example, Dempster and McCorry [45] report that research tends to find strong relationships between the consequences and emotional representations domains on the IPQ-R and queries whether these are separate domains or whether they are both the result of an appraisal of coping resources. A Think Aloud study using the IPQ-R [48] appears to reinforce this. Participants in their study considered the availability of their coping resources before recording their illness perceptions, suggesting that the responses on the IPQ-R are confounded with the assessment of coping.

Indeed, the longitudinal research in this review indicates that coping strategies and illness perceptions change very little over time, even when these variables are assessed shortly after diagnosis. So, although theory suggests that illness perceptions predict coping, if this does happen, then it does so in such a brief period of time that it is difficult or impossible 
to capture separately. Alternatively, if illness perceptions represent the outcome of an appraisal process (as suggested above), then perhaps their relationship with coping and distress outcomes would be more appropriately represented by a model such as the Transactional Model of Stress [49]. In this case, coping would be treated as a moderator in the relationship between illness perceptions and distress outcomes. Some re-analysis of existing data could address this thesis.

It is worth noting that most of the studies included in this review are cross-sectional in nature. Although cross-sectional studies are useful snapshots of the relationship between variables, they do not provide us with any sense of the direction of relationships, which is important in terms of the application of findings. Given the consistency of findings across studies presented in this review, we can conclude that further cross-sectional work in this area is not necessary.

In summary, then, it is clear that illness perceptions (in particular the consequences scale) and coping have an important role to play in the explanation of distress outcomes across a range of physical health conditions. However, some clarity about the position of coping in relation to illness perceptions, and more longitudinal work is needed if we are to apply this information to the design of interventions for the improvement of psychological health among people with long term conditions. 


\section{References}

[1] Leventhal, H., Meyer, D., \& Nerenz, D. (1980). The common sense representation of illness danger. In S. Rachman (Ed.) Medical Psychology, Volume 2 (pp. 7-30). New York: Pergamon Press.

[2] Kucukarslan, S.N. (2012). A review of published studies of patients’ illness perceptions and medication adherence: Lessons learned and future directions. Research in Social and Administrative Pharmacy, 8(5), 371-382. doi: 10.1016/j.sapharm.2011.09.002

[3] Jones, C.J., Smith, H.E. \& Llewellyn, C.D. (2015). A systematic review of the effectiveness of interventions using the Common Sense Self-Regulatory Model to improve adherence behaviours. Journal of Health Psychology, online early doi:10.1177/1359105315583372

[4] Brandes, K. \& Mullan, B. (2014). Can the common-sense model predict adherence in chronically ill patients? A meta-analysis. Health Psychology Review, 8(2), 129-153. doi: $10.1080 / 17437199.2013 .820986$

[5] French, D.P., Cooper, A., \& Weinman, J. (2006). Illness perceptions predict attendance at cardiac rehabilitation following acute myocardial infarction: a systematic review with meta-aanalysis. Journal of Psychosomatic Research, 61(6), 757-767. doi:10.1016/j.jpsychores.2006.07.029

[6] Hudson, J.L., Bundy, C., Coventry, P.A. \& Dickens, C. (2014). Exploring the relationship between cognitive illness representations and poor emotional health and their combined association with diabetes self-care. A systematic review with meta-analysis, Journal of Psychosomatic Research, 76(4), 265-274.

doi.org/10.1016/j.jpsychores.2014.02.004 
[7] McSharry, J., Moss-Morris, R., \& Kendrick, T. (2011). Illness perceptions and glycaemic control in diabetes: a systematic review with meta-analysis. Diabetic Medicine, 28(11), 1300-1310. doi:10.1111/j.1464-5491.2011.03298.x

[8] Graham, C. D., Rose, M. R., Grunfeld, E. A., Kyle, S. D., \& Weinman, J. (2011). A systematic review of quality of life in adults with muscle disease. Journal of Neurology, 258(9), 1581-1592. doi:10.1007/s00415-011-6062-5

[9] Price, A., Goodwin, L., Rayner, L., Shaw, E., Hansford, P., Sykes, N., . . . Lee, W. (2012). Illness perceptions, adjustment to illness, and depression in a palliative care population. Journal of Pain and Symptom Management, 43(5), 819-832. doi:10.1016/j.jpainsymman.2011.05.013

[10] Dempster, M., McCorry, N. K., Brennan, E., Donnelly, M., Murray, L. J., \& Johnston, B. T. (2011). Illness perceptions among carer-survivor dyads are related to psychological distress among oesophageal cancer survivors. Journal of Psychosomatic Research, 70(5), 432-439. doi:10.1016/j.jpsychores.2010.07.007

[11] Benyamini, Y., Goner-Shilo, D., \& Lazarov, A. (2012). Illness perception and quality of life in patients with contact dermatitis. Contact Dermatitis, 67(4), 193-199. doi:10.1111/j.1600-0536.2012.02071.x

[12] Wenninger, K., Helmes, A., Bengel, J., Lauten, M., Voelkel, S., \& Niemeyer, C. M. (2013). Coping in long-term survivors of childhood cancer: Relations to psychological distress. Psycho-Oncology, 22(4), 854-861. doi:10.1002/pon.3073

[13] Moss-Morris, R., Weinman, J., Petrie, K.J., Horne, R., Cameron, L.D., \& Buick, D. (2002). The revised Illness Perception Questionnaire (IPQ-R). Psychology \& Health, 17, 1-16. 
[14] Weinman, J., Petrie, K.J., Moss-Morris, R., \& Horne, R. (1996). The Illness Perception Questionnaire: a new method for assessing the cognitive representations of illness. Psychology \& Health, 11, 431-445.

[15] Broadbent, E., Petrie, K.J., Main, J., \& Weinman, J. (2006). The Brief Illness Perception Questionnaire. Journal of Psychosomatic Research, 60, 631-637. doi: 10.1016/j.jpsychores.2005.10.02

[16] Hagger, M.S., \& Orbell, S. (2003). A meta-analytic review of the common sense model of illness representations. Psychology \& Health, 18(2), 141-184. doi:10.1080/088704403100081321

[17] Juni, P., Bartlett, C., Holenstein, F., \& Sterne, J. (2003). How important are comprehensive literature searches and the assessment of trial quality in systematic reviews? : Empirical study. Health Technology Assessment, 7.

[18] Hunter, J.E., \& Scmidt, F.L. (1990). Methods of meta-analysis: Correcting error and bias in research findings. Newbury Park, CA: Sage.

[19] Dempster, M., McCorry, N. K., Brennan, E., Donnelly, M., Murray, L. J., \& Johnston, B. T. (2011). Do changes in illness perceptions predict changes in psychological distress among oesophageal cancer survivors? Journal of Health Psychology, 16(3), 500-509. doi:10.1177/1359105310386633

[20] Dempster, M., McCorry, N. K., Brennan, E., Donnelly, M., Murray, L., \& Johnston, B. T. (2012). Psychological distress among survivors of esophageal cancer: The role of illness cognitions and coping. Diseases of the Esophagus, 25(3), 222-227. doi:10.1111/j.1442-2050.2011.01233.x

[21] Helder, D., Kaptein, A., van Kempen, G., Weinman, J., van Houwelingen, H., \& Roos, R. (2002). Living with Huntington's Disease: Illness perceptions, coping mechanisms, 
and patients' well-being. British Journal of Health Psychology, 7, 449-462.

doi:10.1348/135910702320645417

[22] Kaptein, A. A., Helder, D. I., Scharloo, M., Van Kempen, G. M. J., Weinman, J., Van Houwelingen, H. J. C., \& Roos, R. A. C. (2006). Illness perceptions and coping explain well-being in patients with Huntington's Disease. Psychology \& Health, 21(4), 431-446. doi:10.1080/14768320500456947

[23] Llewellyn, C. D., McGurk, M., \& Weinman, J. (2006). Head and neck cancer: To what extent can psychological factors explain differences between health-related quality of life and individual quality of life? British Journal of Oral \& Maxillofacial Surgery, 44(5), 351-357. doi:10.1016/j.bjoms.2005.06.033

[24] Llewellyn, C. D., McGurk, M., \& Weinman, J. (2007). The relationship between the patient generated index (PGI) and measures of HR-QoL following diagnosis with head and neck cancer: Are illness and treatment perceptions determinants of judgment-based outcomes? British Journal of Health Psychology, 12, 421-437.

doi:10.1348/135910706X118422

[25] Llewellyn, C. D., McGurk, M., \& Weinman, J. (2007). Illness and treatment beliefs in head and neck cancer: Is Leventhal's common sense model a useful framework for determining changes in outcomes over time? Journal of Psychosomatic Research, 63(1), 1726. doi:10.1016/j.jpsychores.2007.01.013

[26] Zyrianova, Y., Kelly, B. D., Sheehan, J., McCarthy, C., \& Dinan, T. G. (2011). The psychological impact of arthritis: The effects of illness perception and coping. Irish Journal of Medical Science, 180(1), 203-210. doi:10.1007/s11845-010-0522-2

[27] Gandy, M., Sharpe, L., Perry, K. N., Miller, L., Thayer, Z., Boserio, J., \& Mohamed, A. (2013). The psychosocial correlates of depressive disorders and suicide risk in 
people with epilepsy. Journal of Psychosomatic Research, 74(3), 227-232.

doi:10.1016/j.jpsychores.2012.11.001

[28] Goldstein, L., Holland, L., Soteriou, H., \& Mellers, J. (2005). Illness

representations, coping styles and mood in adults with epilepsy. Epilepsy Research, 67(1-2), 1-11. doi:10.1016/j.eplepsyres.2005.06.008

[29] Evans, D., \& Norman, P. (2009). Illness representations, coping and psychological adjustment to Parkinson's Disease. Psychology \& Health, 24(10), 1181-1196. doi:10.1080/08870440802398188

[30] Groarke, A., Curtis, R., Coughlan, R., \& Gsel, A. (2004). The role of perceived and actual disease status in adjustment to rheumatoid arthritis. Rheumatology, 43(9), 11421149. doi:10.1093/rheumatology/keh262

[31] Knibb, R. C., \& Horton, S. L. (2008). Can illness perceptions and coping predict psychological distress amongst allergy sufferers? British Journal of Health Psychology, 13, 103-119. doi:10.1348/135910706X173278

[32] McCabe, P. J., \& Barnason, S. A. (2012). Illness perceptions, coping strategies, and symptoms contribute to psychological distress in patients with recurrent symptomatic atrial fibrillation. Journal of Cardiovascular Nursing, 27(5), 431-444.

doi:10.1097/JCN.0b013e31821e7ab1

[33] McCorry, N. K., Dempster, M., Quinn, J., Hogg, A., Newell, J., Moore, M., . . . Kirk, S. J. (2013). Illness perception clusters at diagnosis predict psychological distress among women with breast cancer at 6 months post diagnosis. Psycho-Oncology, 22(3), 692698. doi:10.1002/pon.3054

[34] Rutter, C., \& Rutter, D. (2002). Illness representation, coping and outcome in irritable bowel syndrome (IBS). British Journal of Health Psychology, 7, 377-391. doi:10.1348/135910702320645372 
[35] Hallas, C. N., Wray, J., Andreou, P., \& Banner, N. R. (2011). Depression and perceptions about heart failure predict quality of life in patients with advanced heart failure. Heart \& Lung, 40(2), 111-121. doi:10.1016/j.hrtlng.2009.12.008

[36] Keeling, M., Bambrough, J., \& Simpson, J. (2013). Depression, anxiety and positive affect in people diagnosed with low-grade tumours: The role of illness perceptions. Psycho-Oncology, 22(6), 1421-1427. doi:10.1002/pon.3158

[37] Orbell, S., O'Sullivan, I., Parker, R., Steele, B., Campbell, C., \& Weller, D. (2008). Illness representations and coping following an abnormal colorectal cancer screening result. Social Science \& Medicine, 67(9), 1465-1474. doi:10.1016/j.socscimed.2008.06.039

[38] Gray, S. E., \& Rutter, D. R. (2007). Illness representations in young people with chronic fatigue syndrome. Psychology \& Health, 22(2), 159-174.

doi:10.1080/14768320600774595

[39] Rutter, C. L., \& Rutter, D. R. (2007). Longitudinal analysis of the illness representation model in patients with irritable bowel syndrome (IBS). Journal of Health Psychology, 12(1), 141-148. doi:10.1177/1359105307071748

[40] Scharloo, M., Kaptein, A., Weinman, J., Hazes, J., Breedveld, F., \& Rooijmans, H. (1999). Predicting functional status in patients with rheumatoid arthritis. Journal of Rheumatology, 26(8), 1686-1693.

[41] Scharloo, M., Kaptein, A., Weinman, J., Bergman, W., Vermeer, B., \& Rooijmans, H. (2000). Patients' illness perceptions and coping as predictors of functional status in psoriasis: A 1-year follow-up. British Journal of Dermatology, 142(5), 899-907. doi:10.1046/j.1365-2133.2000.03469.x

[42] Scharloo, M., Kaptein, A., Weinman, J., Willems, L., \& Rooijmans, H. (2000). Physical and psychological correlates of functioning in patients with chronic obstructive pulmonary disease. Journal of Asthma, 37(1), 17-29. doi:10.3109/02770900009055425 
[43] Chen, S-L., Tsai, J-C., \& Lee, W-L. (2008). Psychometric validation of the Chinese version of the Illness Perception Questionnaire-Revised for patients with hypertension. Journal of Advanced Nursing, 64, 524-534.

[44] Dempster, M., \& McCorry, N. (2012). The factor structure of the revised Illness Perceptions Questionnaire in a population of oesophageal cancer survivors. PsychoOncology, 21(5), 524-530. 10.1002/pon.1927

[45] Giannousi, Z., Manaras, I., Georgoulias, V., \& Samonis, G. (2010). Illness perceptions in greek patients with cancer: A validation of the revised-illness perception questionnaire. Psycho-Oncology, 19(1), 85-92. doi:10.1002/pon.1538

[46] O’Brien, C.W. \& Moorey, S. (2010). Outlook and adaptation in advanced cancer: a systematic review. Psycho-Oncology, 19(12), 1239-1249. doi: 10.1002/pon.1704

[47] Vriezekolk, J.E., van Lankveld, W.G., Geenen, R., \& van den Ende, C.H. (2011). Longitudinal association between coping and psychological distress in rheumatoid arthritis: a systematic review. Annals of Rheumatic Disease, 70(7), 1243-1250. doi: 10.1136/ard.2010.143271

[48] McCorry, N. K., Scullion, L., McMurray, C. M., Houghton, R., \& Dempster, M. (2013). Content validity of the illness perceptions questionnaire - revised among people with type 2 diabetes: A think-aloud study. Psychology \& Health, 28(6), 675-685. doi:10.1080/08870446.2012.746690

[49] Lazarus, R.S. \& Folkman, S. (1984). Stress, Appraisal and Coping. New York: Springer.

[50] Cartwright, T., Endean, N., \& Porter, A. (2009). Illness perceptions, coping and quality of life in patients with alopecia. British Journal of Dermatology, 160(5), 1034-1039. doi:10.1111/j.1365-2133.2008.09014.x 
[51] Dorrian, A., Dempster, M., \& Adair, P. (2009). Adjustment to inflammatory bowel disease: The relative influence of illness perceptions and coping. Inflammatory Bowel Diseases, 15(1), 47-55. doi:10.1002/ibd.20583

[52] Kiebles, J. L., Doerfler, B., \& Keefer, L. (2010). Preliminary evidence supporting a framework of psychological adjustment to inflammatory bowel disease. Inflammatory Bowel Diseases, 16(10), 1685-1695. doi:10.1002/ibd.21215

[53] Murphy, H., Dickens, C., Creed, F., \& Bernstein, R. (1999). Depression, illness perception and coping in rheumatoid arthritis. Journal of Psychosomatic Research, 46(2), 155-164. doi:10.1016/S0022-3999(98)00073-7

[54] Sargeant, H. A., \& O'Callaghan, F. (2009). Predictors of psychological wellbeing in a sample of women with vulval pain. Journal of Reproductive Medicine, 54(2), 109116.

[55] Sharpe, L., Sensky, T., \& Allard, S. (2001). The course of depression in recent onset rheumatoid arthritis - the predictive role of disability, illness perceptions, pain and coping. Journal of Psychosomatic Research, 51(6), 713-719. doi:10.1016/S00223999(01)00266-5 
Table 1

Description of Review Studies

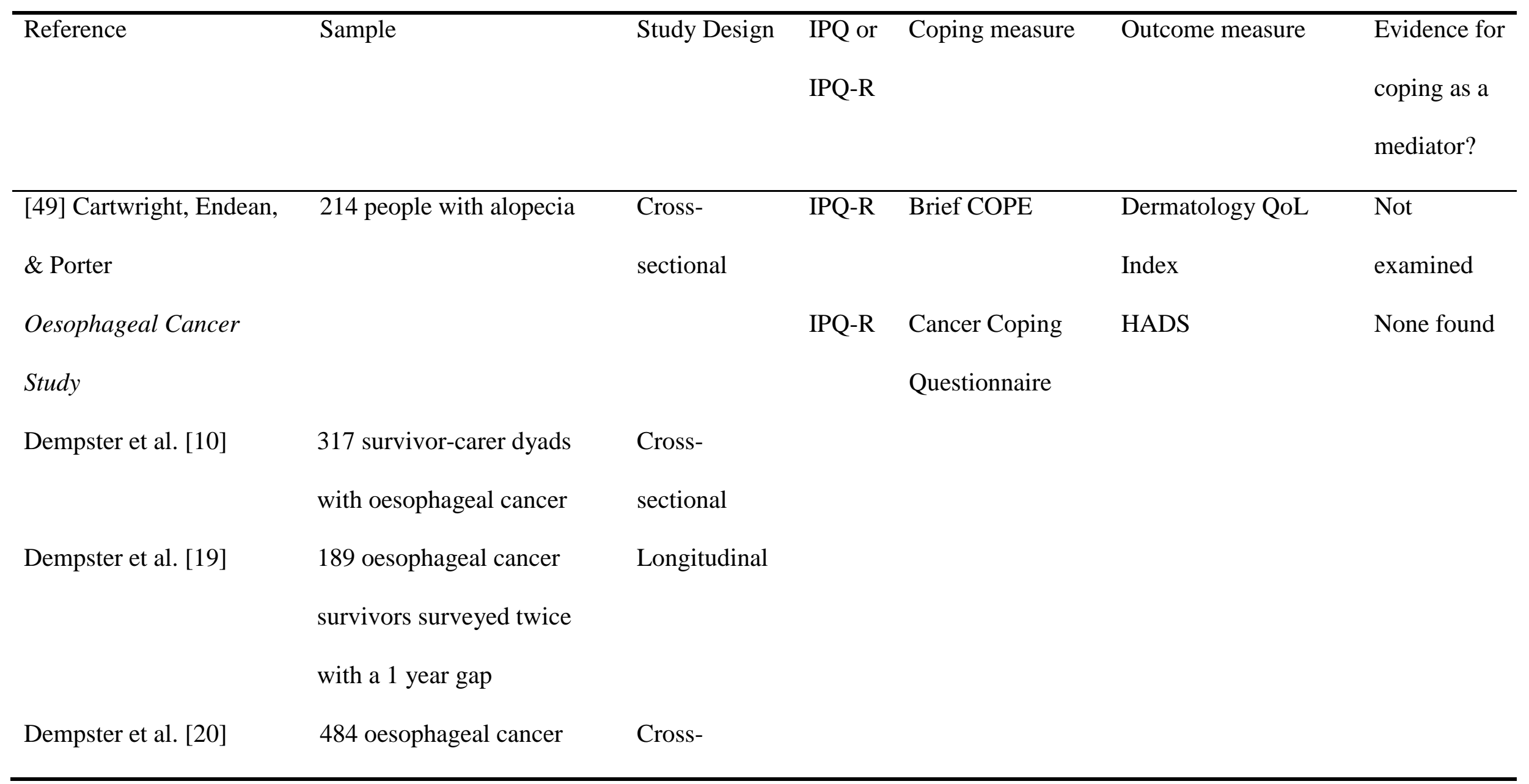


[51] Dorrian, Dempster,

80 adults with inflammatory Cross-

sectional

\& Adair

bowel disease

sectional

[29] Evans \& Norman

58 adults with Parkinson's

Disease

[27] Gandy et al.

123 patients with epilepsy

[28] Goldstein et al.

43 adults with epilepsy

[38] Gray \& Rutter
85 young people with CFS
Cross-

sectional

Cross-

sectional

Longitudinal
IPQ-R Medical Coping
Modes

Questionnaire

IPQ

Ways of Coping

Scale - Revised

IPQ Ways of Coping

Cross-

IPQ-R Illness

sectional management
Mini International

Neuropsychiatric

Interview

HADS

Not

examined

Yes, for

depression

and anxiety

Not

examined

Quality of Life Scale Yes, for

QoL 


\begin{tabular}{|c|c|c|c|c|c|c|}
\hline & & & & Questionnaire & & \\
\hline \multirow[t]{2}{*}{ [35] Hallas et al. } & 146 adults with advanced & Cross- & IPQ-R & COPE & HADS, WHOQOL- & Not \\
\hline & heart failure & sectional & & & Bref, MLWHF & examined \\
\hline Huntington's Disease & 77 adults with Huntington's & Cross- & IPQ & COPE & SF36; SIP & None found \\
\hline Study & Disease & sectional & & & & \\
\hline \multicolumn{7}{|l|}{ Helder et al. [21]; Kaptein } \\
\hline \multicolumn{7}{|l|}{ et al. [22] } \\
\hline \& Simpson & brain tumour & sectional & & & & examined \\
\hline [52] Kiebles, Doerfler, \& & 38 adults with IBD & Cross- & IPQ-R & Brief COPE & IBDQ, SF12 & Not \\
\hline Keefer & & sectional & & & & examined \\
\hline [31] Knibb \& Horton & 156 people with allergy & Cross- & IPQ-R & $\mathrm{COPE}$ & Perceived Stress & Yes, for \\
\hline
\end{tabular}









\begin{tabular}{|c|c|c|c|c|c|c|}
\hline \multirow{4}{*}{ [53] Murphy et al. (1999) } & cancer at 2 time points 6 & & \multirow{4}{*}{ IPQ } & \multicolumn{2}{|l|}{ Questionnaire } & \\
\hline & months apart & & & & \multirow{3}{*}{ HADS-depression } & \\
\hline & 62 adults with rheumatoid & Cross- & & London Coping & & Not \\
\hline & arthritis & sectional & & with RA & & examined \\
\hline \multirow{3}{*}{ [37] Orbell et al. } & & & & Questionnaire & & \multirow{3}{*}{ None found } \\
\hline & 697 adults after abnormal & Cross- & IPQ-R & Ways of Coping & State Anxiety & \\
\hline & colonoscopy & sectional & & & Inventory & \\
\hline \multirow[t]{3}{*}{ [34] Rutter \& Rutter } & 209 adults with irritable & Cross- & IPQ & COPE & HADS & Yes, for \\
\hline & bowel syndrome & sectional & & & & depression \\
\hline & & & & & & and anxiety \\
\hline \multirow[t]{3}{*}{ [39] Rutter \& Rutter } & 37 adults with irritable & Longitudinal & IPQ & COPE & HADS & Not \\
\hline & bowel syndrome at 3 time & & & & & examined \\
\hline & points & & & & & \\
\hline [54] Sargeant \& & 97 women with vulval pain & Cross- & IPQ-R & Brief COPE & SF36 (mental health) & Not \\
\hline O'Callaghan & & sectional & & & & examined \\
\hline
\end{tabular}




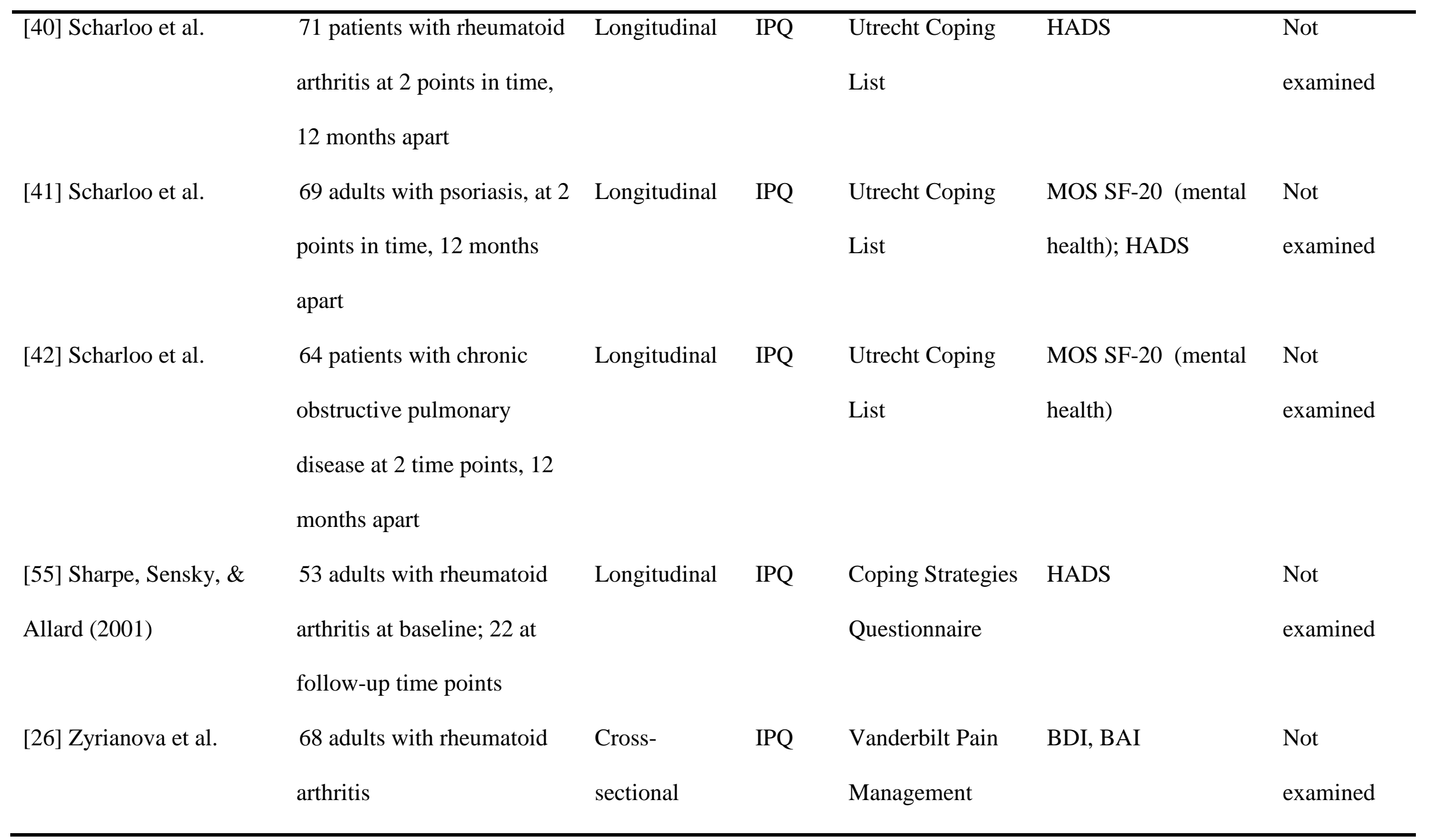


Inventory (active

and passive

coping)

IPQ: Illness Perception Questionnaire; IPQ-R: Illness Perception Questionnaire-Revised; COPE: Coping Orientation to Problems

Experienced; HADS: Hospital Anxiety and Depression Scale 
Table 2

Meta-analysis for relationships between depression and illness perceptions and coping

\begin{tabular}{|c|c|c|c|c|}
\hline & $\begin{array}{c}\text { Weighted } \\
\text { Average } \\
\text { correlation* }\end{array}$ & $95 \%$ CI & $\begin{array}{l}\text { Heterogeneity } \\
\text { chi-square, p }\end{array}$ & $\begin{array}{c}\text { Number of } \\
\text { studies }\end{array}$ \\
\hline \multicolumn{5}{|l|}{ Illness Perceptions } \\
\hline Identity & 0.29 & 0.22 to 0.37 & $31.27,<.001$ & $11(n=1637)$ \\
\hline Timeline & 0.11 & 0.067 to 0.15 & $0.88, .830$ & $4(n=469)$ \\
\hline Consequences & 0.36 & 0.31 to 0.41 & $15.56, .113$ & $11(n=1637)$ \\
\hline Control/cure & -0.30 & -0.33 to -0.27 & $6.46, .039$ & $3(n=346)$ \\
\hline Acute/chronic & 0.07 & 0.01 to 0.14 & $5.50, .240$ & $5(n=1051)$ \\
\hline Cyclical & 0.18 & 0.12 to 0.23 & $5.96, .311$ & $6(n=1125)$ \\
\hline Personal control & -0.22 & -0.31 to -0.12 & $17.29, .004$ & $6(n=1125)$ \\
\hline Treatment control & -0.18 & -0.24 to -0.12 & $5.29, .259$ & $5(\mathrm{n}=1051)$ \\
\hline Coherence & -0.24 & -0.31 to -0.17 & $9.88, .079$ & $6(n=1125)$ \\
\hline $\begin{array}{l}\text { Emotional } \\
\text { representations }\end{array}$ & 0.52 & 0.48 to 0.57 & $5.84, .211$ & $5(\mathrm{n}=1051)$ \\
\hline \multicolumn{5}{|l|}{ Coping Strategies } \\
\hline Positive focus & -0.16 & -0.25 to -0.07 & 23.96, .001 & $8(n=1337)$ \\
\hline Venting & 0.41 & 0.30 to 0.53 & $11.52, .009$ & $4(n=583)$ \\
\hline Acceptance & -0.19 & -0.23 to 0.15 & $1.53, .821$ & $5(n=668)$ \\
\hline $\begin{array}{l}\text { Behavioral } \\
\text { disengagement }\end{array}$ & 0.29 & 0.18 to 0.40 & 13.62, .008 & $5(n=658)$ \\
\hline
\end{tabular}

* Calculated using the Hunter-Schmidt (1990) method 
Table 3

Meta-analysis for relationships between anxiety and illness perceptions and coping

\begin{tabular}{|c|c|c|c|c|}
\hline & $\begin{array}{c}\text { Weighted } \\
\text { Average } \\
\text { correlation* }\end{array}$ & $95 \%$ CI & $\begin{array}{l}\text { Heterogeneity } \\
\text { chi-square, p }\end{array}$ & $\begin{array}{c}\text { Number of } \\
\text { studies }\end{array}$ \\
\hline \multicolumn{5}{|l|}{ Illness Perceptions } \\
\hline Identity & 0.32 & 0.24 to 0.39 & 19.49, .007 & $8(n=1377)$ \\
\hline Consequences & 0.34 & 0.27 to 0.41 & $17.66, .014$ & $8(n=1377)$ \\
\hline Acute/chronic & 0.12 & 0.06 to 0.18 & $4.98, .290$ & $5(n=1051)$ \\
\hline Cyclical & 0.25 & 0.21 to 0.29 & 3.07, .689 & $6(n=1125)$ \\
\hline Personal control & -0.10 & -0.16 to -0.03 & $6.87, .230$ & $6(n=1125)$ \\
\hline Treatment control & -0.17 & -0.24 to -0.09 & 7.84,.098 & $5(n=1051)$ \\
\hline Coherence & -0.26 & -0.34 to -0.17 & 14.08, .015 & $6(n=1125)$ \\
\hline $\begin{array}{l}\text { Emotional } \\
\text { representations }\end{array}$ & 0.64 & 0.56 to 0.72 & $25.11,<.001$ & $5(n=1051)$ \\
\hline \multicolumn{5}{|l|}{ Coping Strategies } \\
\hline Positive focus & -0.07 & -0.18 to 0.04 & 11.07, .011 & $4(n=921)$ \\
\hline Venting & 0.49 & 0.42 to 0.57 & $6.16, .104$ & $4(n=583)$ \\
\hline Denial & 0.25 & 0.07 to 0.43 & 10.41, .005 & $3(n=376)$ \\
\hline Acceptance & -0.24 & -0.29 to -0.18 & 0.97, .615 & $3(n=437)$ \\
\hline Active coping & -0.13 & -0.21 to -0.04 & $2.44, .295$ & $3(n=437)$ \\
\hline
\end{tabular}

* Calculated using the Hunter-Schmidt (1990) method

Timeline and control/cure missing as only 1 study reported a correlation coefficient for these IPQ scales. 
Figure 1

Results of review search strategy
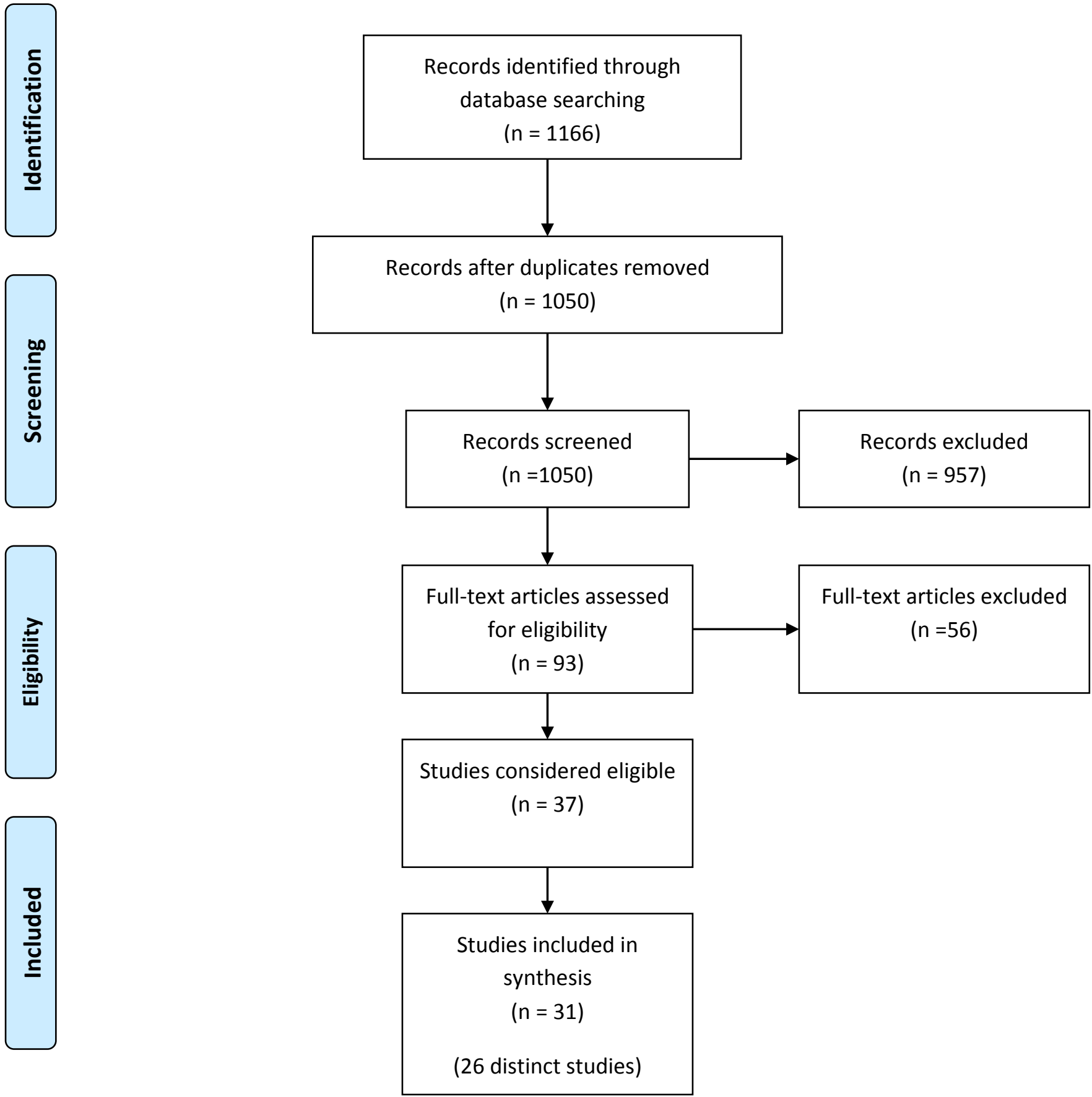